This document is the Accepted Manuscript version of a Published Work that appeared in final form in Journal of the American Chemical Society, copyright (c) American Chemical Society after peer review and technical editing by the publisher. To access the final edited and published work see: https://dx.doi.org/10.1021/jacs.8b11210. 


\title{
Unraveling the impact of halide mixing on perovskite stability
}

\author{
Jeremy Hieulle ${ }^{1, \$}$, Xiaoming Wang ${ }^{2, \$}$, Collin Stecker ${ }^{1}$, Dae-Yong Son ${ }^{1}$, Longbin Qiu ${ }^{1}$, Robin \\ Ohmann ${ }^{1, \uparrow}$, Luis K. Ono ${ }^{1}$, Aitor Mugarza ${ }^{3,4}$, Yanfa Yan ${ }^{2, *}$, and Yabing Qi ${ }^{1, *}$ \\ ${ }^{1}$ Energy Materials and Surface Sciences Unit (EMSSU), Okinawa Institute of Science and Technology Graduate University \\ (OIST), 1919-1 Tancha, Onna-son, Okinawa 904-0495, Japan. \\ ${ }^{2}$ Department of Physics and Astronomy and Wright Center for Photovoltaics Innovation and Commercialization, The Uni- \\ versity of Toledo, Toledo, Ohio 43606, United States. \\ ${ }^{3}$ Catalan Institute of Nanoscience and Nanotechnology (ICN2), Consejo Superior de Investigaciones Científicas (CSIC) and \\ The Barcelona Institute of Science and Technology, Campus UAB, Bellaterra, 08193 Barcelona, Spain.
}

${ }^{4}$ ICREA-Institució Catalana de Recerca i Estudis Avançats, 08010 Barcelona, Spain.

\begin{abstract}
Increasing the stability of perovskites is essential for their integration in commercial photovoltaic devices. Halide mixing is suggested as a powerful strategy toward stable perovskite materials. However, the stabilizing effect of the halides critically depends on their distribution in the mixed compound, a topic that is currently under intense debate. Here we successfully determine the exact location of the I and $\mathrm{Cl}$ in the mixed $\mathrm{CH}_{3} \mathrm{NH}_{3} \mathrm{PbBr}_{3-\mathrm{y}} \mathrm{I}_{\mathrm{y}}$ and $\mathrm{CH}_{3} \mathrm{NH}_{3} \mathrm{PbBr}_{3-\mathrm{z}} \mathrm{Cl}_{\mathrm{z}}$ perovskite lattices and correlate it with the enhanced stability we find for the latter. By combining scanning tunneling microscopy (STM) and density functional theory (DFT), we predict that for low ratios, iodine and chlorine incorporation have opposite effects on the electronic properties and stability of the $\mathrm{CH}_{3} \mathrm{NH}_{3} \mathrm{PbBr}_{3}$ perovskite material. In addition, we determine an ideal halide ratio for stability increase without detrimental bandgap modification, providing an important direction for the fabrication of stable perovskite devices. The increased material stability induced by chlorine incorporation is verified by performing photoelectron spectroscopy on a device architecture. Our findings provide an answer to the current debate on halide incorporation and demonstrate their direct influence on device stability.
\end{abstract}

\section{INTRODUCTION}

Metal halide perovskite materials have been the focus of intense investigation due to their low cost and superior photovoltaic performance, with record power conversion efficiencies exceeding $23.3 \%{ }^{1}$. Despite numerous advantages, their poor stability hinders commercialization of perovskite-based devices. To increase perovskite stability various strategies have been envisaged $^{2,3}$. Mixing different halides ( $\mathrm{I}, \mathrm{Br}, \mathrm{Cl}$ ) has been shown both experimentally and theoretically to have a strong impact on the device performance and stability ${ }^{4-9}$. For example, a small addition of bromine ${ }^{10}$ or chlorine ${ }^{11}$ confers increased device lifetime compared to pure iodide $\left(\mathrm{CH}_{3} \mathrm{NH}_{3} \mathrm{PbI}_{3}\right)$ based devices. Addition of $\mathrm{Cl}$ to $\mathrm{CH}_{3} \mathrm{NH}_{3} \mathrm{PbBr}_{3}$ films improves carrier recombination lifetime ${ }^{12}$ and increases open circuit voltage ${ }^{13,14}$. However, the role of $\mathrm{Cl}$ and the extent of its incorporation into the crystal lattice remain a topic of debate, with conflicting results reported in the literature ${ }^{15-21}$. Here, we choose to mix $\mathrm{CH}_{3} \mathrm{NH}_{3} \mathrm{PbBr}_{3}$ perovskite with two different halides, I and $\mathrm{Cl}$, that have different ionic radii and bond strengths with $\mathrm{Pb}$. In this way, the effect of the incorporation of a larger ion $(\mathrm{I}>\mathrm{Br})$ and a smaller ion $(\mathrm{Cl}<\mathrm{Br})$ can be addressed. In this work, combining scanning tunneling microscopy (STM), density functional theory (DFT) and UV/x-ray photoelectron spectroscopy (UPS/XPS), we reveal the exact location of I and $\mathrm{Cl}$ anions in the perovskite structure, and demonstrate the impact of halideincorporation on the material electronic properties and stability. Furthermore, we determine the ideal $\mathrm{Cl}$-incorporation ratio for stability increase without detrimental bandgap modification.

\section{RESULTS AND DISCUSSION}

$\mathrm{CH}_{3} \mathrm{NH}_{3} \mathrm{PbBr}_{3}$ perovskite thin films were prepared on a clean $\mathrm{Au}(111)$ surface $^{22}$ via molecular beam epitaxy in an ultrahigh vacuum environment. The thickness of the ultra-thin film was approximately $4 \pm 1 \mathrm{~nm}$. Scanning tunneling microscopy (STM) images reveal a pair motif similar to the characteristic surface reconstruction previously observed for $\mathrm{CH}_{3} \mathrm{NH}_{3} \mathrm{PbBr}_{3}$ single crystals $^{23-25}$ showing the (010) surface termination (Figure 1a). The bright spots in the STM images correspond to bromine ions of the top layer perovskite structure. For pure $\mathrm{CH}_{3} \mathrm{NH}_{3} \mathrm{PbBr}_{3}$ all the bromine ions have the same height and width in the STM topographs. 

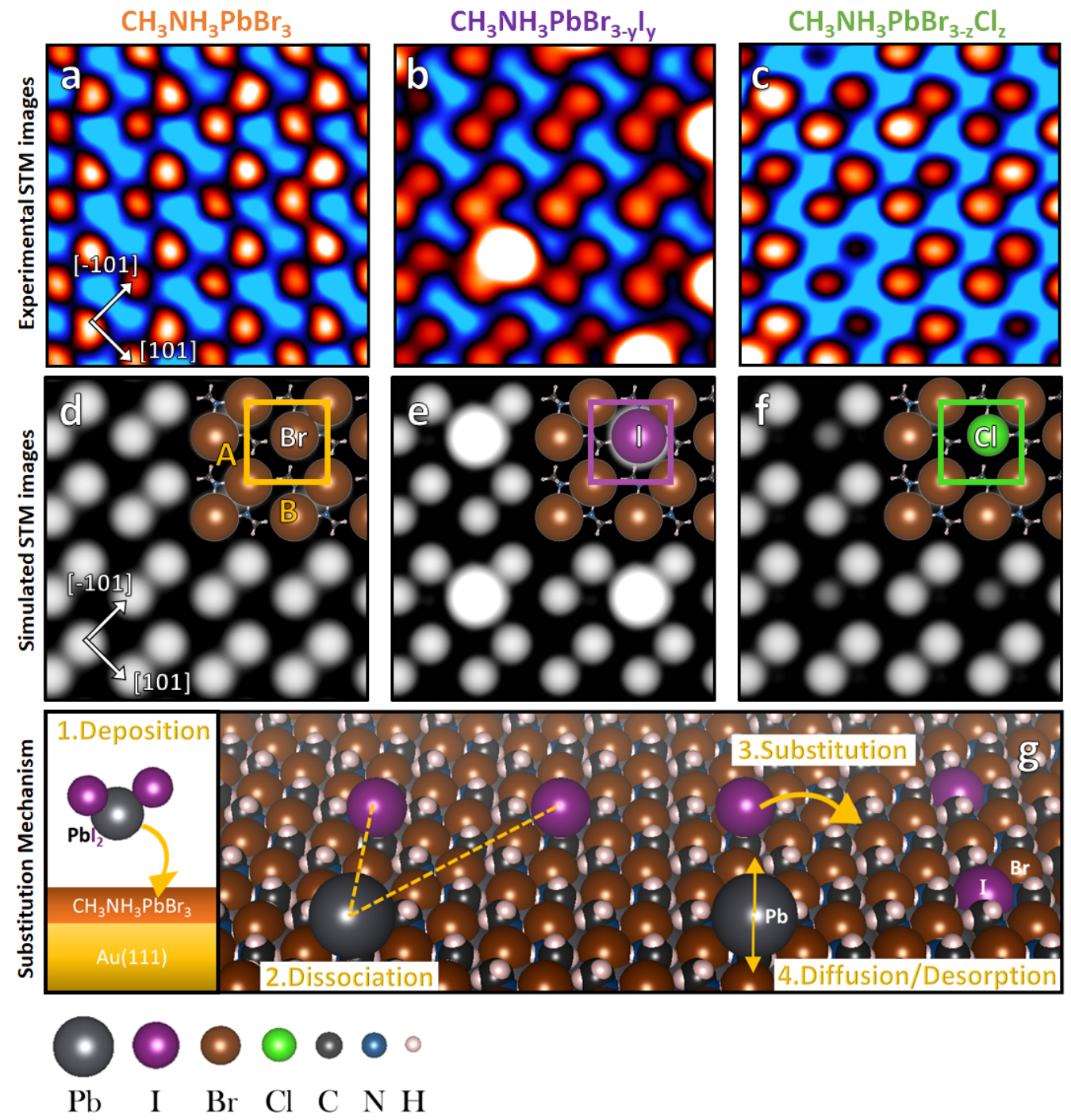

Figure 1. Halide substitution at the perovskite surface. a-c Scanning tunneling microscopy images of $\mathrm{CH}_{3} \mathrm{NH}_{3} \mathrm{PbBr}_{3}(\mathrm{a}), \mathrm{CH}_{3} \mathrm{NH}_{3} \mathrm{PbBr}_{3}-$ ${ }_{y} \mathrm{I}_{\mathrm{y}}(\mathrm{b})$, and $\mathrm{CH}_{3} \mathrm{NH}_{3} \mathrm{PbBr}_{3-\mathrm{z}} \mathrm{Cl}_{\mathrm{z}}$ (c) perovskite surfaces. d-f Calculated (010) surface of the mixed halide organic-inorganic perovskites. Inset: Corresponding surface structure and unit-cell. The lattice unit-cell of pristine $\mathrm{CH}_{3} \mathrm{NH}_{3} \mathrm{PbBr}_{3}$ is square with the following parameters: $\mathrm{A}=\mathrm{B}$ $=7.4 \AA$, and was found to not be altered by the deposition of $\mathrm{PbI}_{2}$ or $\mathrm{PbCl}_{2}$ molecules. The size of $\mathrm{Br}, \mathrm{I}$ and $\mathrm{Cl}$ ions were multiplied by a factor of 4.5 for better visibility. g) Scheme of the substitution mechanism occurring at the surface of $\mathrm{CH}_{3} \mathrm{NH}_{3} \mathrm{PbBr}_{3}$ perovskite after deposition of $\mathrm{PbI}_{2}$ or $\mathrm{PbCl}_{2}$ molecules (Only the $\mathrm{PbI}_{2}$ case is presented for clarity, but $\mathrm{PbCl}_{2}$ is following the same mechanism). Image parameters: (a) Bias $=+1.3 \mathrm{~V}$, Current $=80 \mathrm{pA}$; (b) $+2.0 \mathrm{~V}, 120 \mathrm{pA}$; (c) $-1.9 \mathrm{~V}, 19 \mathrm{pA}$; Image size: (a-c) $2.3 \mathrm{~nm} \times 2.3 \mathrm{~nm}$.

Thereafter, $\mathrm{PbI}_{2}$ or $\mathrm{PbCl}_{2}$ was deposited on the pure $\mathrm{CH}_{3} \mathrm{NH}_{3} \mathrm{PbBr}_{3}$ film kept at room temperature (see Methods). Distinct protrusions with different apparent height and width appear in the perovskite films (Figures 1b, 1c). After deposition of $\mathrm{PbI}_{2}$, strong bright spots appear with an estimated height of $40 \pm 10 \mathrm{pm}$ (Figure 2f) higher than the surrounding $\mathrm{Br}$ ions and with larger diameters (Figure 1b). In contrast, after $\mathrm{PbCl}_{2}$ deposition, slightly darker spots are evident, with smaller diameters and a lower apparent height (Figure 1c). These dark spots appear $20 \pm 10$ pm lower than the neighboring bromine ions.

To unravel the origin of the dark and bright protrusions observed at the surface of the perovskite films, we performed DFT calculations. The atomic structures, as well as the projected density of states (PDOS), of the perovskite films were determined using the VASP code (see Methods). First the pair structure of the $(010)$ top layer surface of $\mathrm{CH}_{3} \mathrm{NH}_{3} \mathrm{PbBr}_{3}$ perovskite was reproduced using DFT and taken as a reference (Figure 1d). Thereafter the impact of $\mathrm{PbI}_{2}$ and $\mathrm{PbCl}_{2}$ deposition on the atomic structure of the perovskites was further addressed by DFT. Different scenarios were considered such as, the adsorption of the entire $\mathrm{PbI}_{2} / \mathrm{PbCl}_{2}$ molecules, as well as the adsorption or substitution of $\mathrm{Pb}, \mathrm{I}$, and $\mathrm{Cl}$ at the $\mathrm{CH}_{3} \mathrm{NH}_{3} \mathrm{PbBr}_{3}$ surface. The best match between the STM experimental results and DFT simulation is found for the dissociation of the $\mathrm{PbI}_{2}\left(\right.$ or $\left.\mathrm{PbCl}_{2}\right)$ molecule, followed by the substitution of $\mathrm{Br}$ by I (or $\mathrm{Cl}$ ). The schematic drawing for the iodine case is shown in Figure $1 \mathrm{~g}$ as an example. We thus assign the bright and dark protrusions observed in our STM experiment respectively to $\mathrm{I}$ and $\mathrm{Cl}$ ions, that substitute $\mathrm{Br}$ ions at the surface of the perovskite film (Figures 1e, 1f). These scenarios are the most energetically favorable 
ones, and the corresponding simulated STM images best reproduce our experimental data (supplementary note 1). Thus, by depositing $\mathrm{PbI}_{2}$ or $\mathrm{PbCl}_{2}$ on a pristine $\mathrm{CH}_{3} \mathrm{NH}_{3} \mathrm{PbBr}_{3}$ film, two different mixed-halide perovskites, $\mathrm{CH}_{3} \mathrm{NH}_{3} \mathrm{PbBr}_{3-\mathrm{y}} \mathrm{I}_{\mathrm{y}}$ and $\mathrm{CH}_{3} \mathrm{NH}_{3} \mathrm{PbBr}_{3-\mathrm{z}} \mathrm{Cl}_{\mathrm{z}}$, were formed.

Large-scale STM images of the surface topography show that the additional bright and dark spots observed after $\mathrm{PbI}_{2}$ and $\mathrm{PbCl}_{2}$ deposition are randomly distributed at the surface of the perovskite films without any long-range order (Figures $2 b, 2 c$ ). These findings are supported by the Fast Fourier Transform (FFT) of the STM images, which do not show any additional peak at low k-values for the mixed perovskite compared to pristine $\mathrm{CH}_{3} \mathrm{NH}_{3} \mathrm{PbBr}_{3}$. The distribution of the different apparent heights that are measured at the surface of the three films is given in Figures 2d-f. While for the pristine perovskite only a single peak is present corresponding to $\mathrm{Br}$ ions, additional peaks show up for the mixed halide perovskites corresponding to I and $\mathrm{Cl}$ ions, respectively. Surprisingly, the substitution of $\mathrm{Br}$ by I or $\mathrm{Cl}$ does not significantly change the lattice unit cell (i.e., lateral structure) of the perovskite surface. However, the vertical positions of the $\mathrm{I}$ and $\mathrm{Cl}$ were found to be different than the $\mathrm{Br}$ ions in pristine $\mathrm{CH}_{3} \mathrm{NH}_{3} \mathrm{PbBr}_{3}$. The iodine ions are slightly upshifted with respect to the Br plane (Figure $2 \mathrm{~h}$ ). Additionally, the iodine ions have a larger ionic radius than bromine. Both the upshift and larger radius contribute to the observed topographic height increase. In contrast, the chlorine ions are downshifted and have a smaller ionic radius compared to $\mathrm{Br}$ (Figure 2i) explaining their lower apparent height.
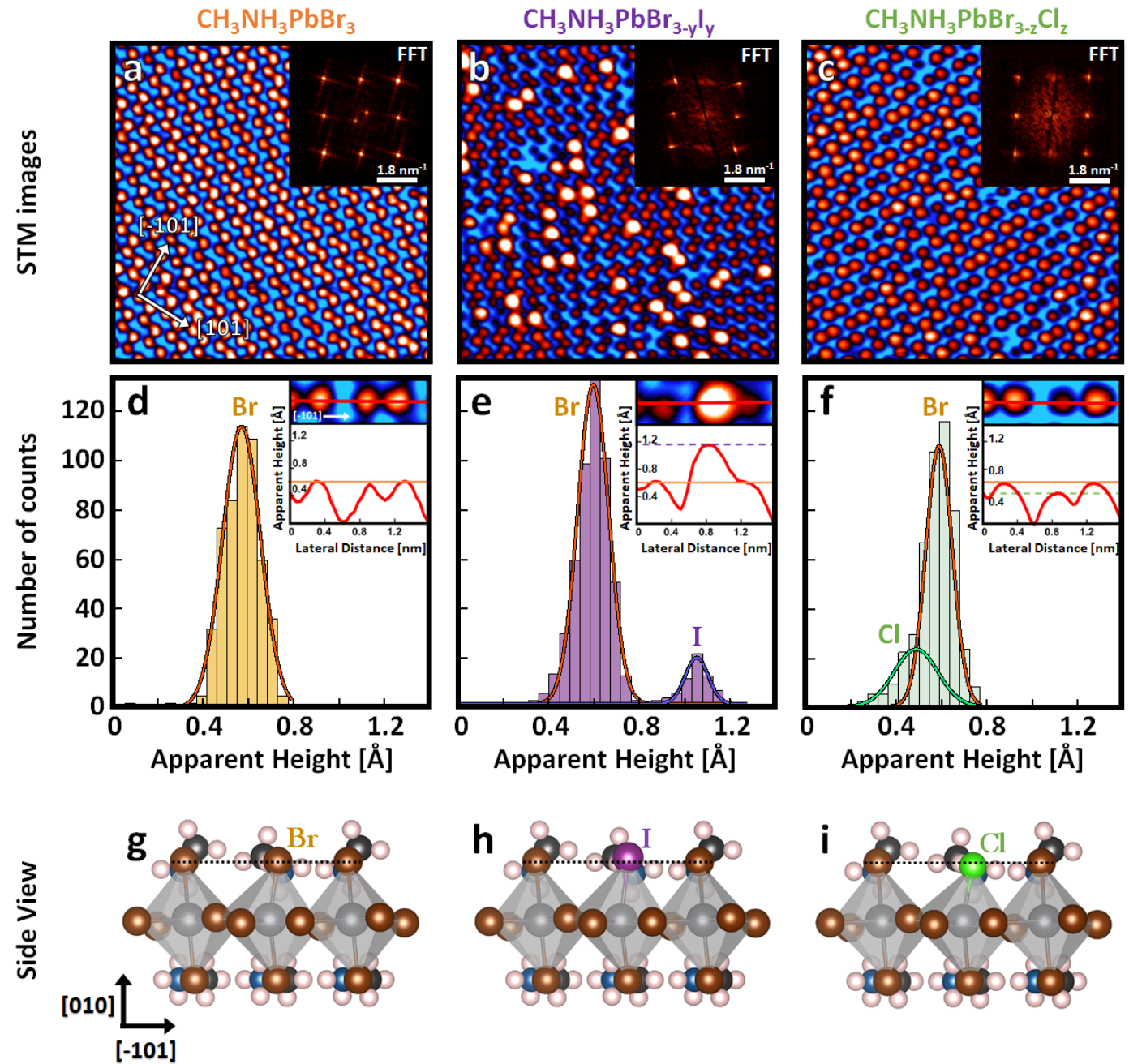

Figure 2. Disordered atomic structure of mixed halide perovskites. (a-c) Large area STM images (10 nm x $10 \mathrm{~nm})$ of the (010) surface of pristine $\mathrm{CH}_{3} \mathrm{NH}_{3} \mathrm{PbBr}_{3}$ (a), and mixed $\mathrm{CH}_{3} \mathrm{NH}_{3} \mathrm{PbBr}_{3-\mathrm{y}} \mathrm{I}_{\mathrm{y}}$ (b), $\mathrm{CH}_{3} \mathrm{NH}_{3} \mathrm{PbBr}_{3-\mathrm{z}} \mathrm{Cl}_{\mathrm{z}}$ (c) perovskites. Scan parameters: (a) Bias=+1.3 V, Current $=80 \mathrm{pA}$; (b) $+2.0 \mathrm{~V}, 120 \mathrm{pA}$; (c) $-2.0 \mathrm{~V}, 100 \mathrm{pA}$. Inset: Fast Fourier Transform (FFT) obtained from the topographic STM images showing no additional peak at low k-values for the mixed-halide perovskite, suggesting that there is no long-range order of the additional iodine and chlorine ions at the surface. d-f Histogram of the apparent height distribution of local maxima (ions). The main peaks correspond to the $\mathrm{Br}$ ions, while the small additional peaks are associated to iodine and chlorine ions (e and f, respectively). Inset: typical profiles obtained for the different halides $(\mathrm{Br}, \mathrm{I}, \mathrm{Cl})$ at the perovskite surface. g-i Relative positions of the halides with respect to the top $\mathrm{CH}_{3} \mathrm{NH}_{3} \mathrm{Br}$ surface. The dashed black lines are a guide for the eyes to show the respective positions and heights of the $\mathrm{Br}, \mathrm{I}$ and $\mathrm{Cl}$ ions. Color code: $\mathrm{Pb}$ (gray), $\mathrm{Br}$ (brown), I (purple), $\mathrm{Cl}$ (green), C (black), N (light blue), $\mathrm{H}$ (white). 
Besides the single bright and dark protrusions, which are attributed to the substitution of $\mathrm{Br}$ with $\mathrm{I}$ or $\mathrm{Cl}$, we observed pairs and clusters of bright and dark protrusions (Figure S3). They are attributed to $\mathrm{I}$ or $\mathrm{Cl}$ ions that substitute multiple bromines of the perovskite surface. Two types of pairs are found on the surface. Iodine and chlorine pairs can be formed either by substitution of two bromine ions within the same pair, or by the substitution of two neighboring $\mathrm{Br}$ ions within two adjacent pairs (Figure S3). DFT calculations shows that the chemical nature of the halides strongly influences the stability of the pair. The energy barrier for the formation of two isolated $\mathrm{Cl}-\mathrm{Br}$ pairs is lower than the energy formation of a single $\mathrm{Cl}-\mathrm{Cl}$ pair $\left(\mathrm{E}_{2(\mathrm{Cl}-\mathrm{Br})}\right.$ $\left.<\mathrm{E}_{\mathrm{Cl}-\mathrm{Cl}}\right)$. These results suggest that at low coverage the chlorine ions prefer to form isolated $\mathrm{Cl}-\mathrm{Br}$ pairs rather than clustering together to form $\mathrm{Cl}-\mathrm{Cl}$ pairs or phase segregating. The same trend was found for the iodine case, i.e., $\mathrm{E}_{2(\mathrm{I}-\mathrm{Br})}<\mathrm{E}_{\mathrm{I}-\mathrm{I}}$ (Table $\mathrm{S} 1$ ). This is the reason why the substituting halide ions were found to be randomly distributed at the surface of the perovskite, leading to the disordered atomic structure observed in the experiment.

Ultraviolet photoemission spectroscopy (UPS) experiments were performed on the mixed perovskites to correlate their atomic structures with their electronic properties (Figure 3). The valence band (VB) spectra of the perovskite films are composed of 6 main peaks (A-F) as shown in Figure 3. A strong modification of the valence band lineshape can be observed when substituting bromine ions at the surface with iodine or chlorine. Based on DFT calculations, we found that the VB of pristine $\mathrm{CH}_{3} \mathrm{NH}_{3} \mathrm{PbBr}_{3}$ is composed mainly of $\mathrm{Br} \boldsymbol{p} \boldsymbol{x}$, $\boldsymbol{p} \boldsymbol{y}$, and $\boldsymbol{p} \boldsymbol{z}$ hybridized states with a small contribution from the $\mathrm{Pb} s$ and $p$ orbitals (Figure $3 b$ ). In addition to these states, contributions of $\mathrm{I}$ and $\mathrm{Cl}$ appear in the $\mathrm{VB}$ of mixed perovskites. The substituting halides are responsible for the valence band modification as observed in the experiment. A higher binding energy was found for $\mathrm{Cl}$ as compared to $\mathrm{Br}$ and $\mathrm{I}$ (Figure $3 \mathrm{~b}$ ), in line with the higher stability of the chlorine-mixed perovskite $\left(\mathrm{CH}_{3} \mathrm{NH}_{3} \mathrm{PbBr}_{3-\mathrm{z}} \mathrm{Cl}_{\mathrm{z}}\right)$ as discussed later. Additionally, the impact of halide substitution on the material work-function was revealed by UPS. A work-function of $4.77 \mathrm{eV}$ was measured for pristine $\mathrm{CH}_{3} \mathrm{NH}_{3} \mathrm{PbBr}_{3}$, similar to the values reported in literature $^{26-28}$, while a decrease of $0.2 \mathrm{eV}$ of the work function $(\phi)$ was observed after chlorine substitution $(\phi=4.57 \mathrm{eV})$. Interestingly after iodine incorporation in the perovskite film, the work function was $4.79 \mathrm{eV}$, closer to the original value of pristine $\mathrm{CH}_{3} \mathrm{NH}_{3} \mathrm{PbBr}_{3}$ (Figure S5). We found that the work-function changes originate from a downshift of the vacuum level induced by a modification of the surface dipole moment after halide incorporation (Figure S6). A larger dipole moment amplitude results in a stronger downshift of the vacuum level, and thus a smaller work function $\left(\phi_{\mathrm{I}}>\phi_{\mathrm{Br}}>\phi_{\mathrm{Cl}}\right)$. The possibility of adjusting the work-function as well as the vacuum level position through halide substitution is of prime interest for engineering energy level alignment in perovskite-based devices.
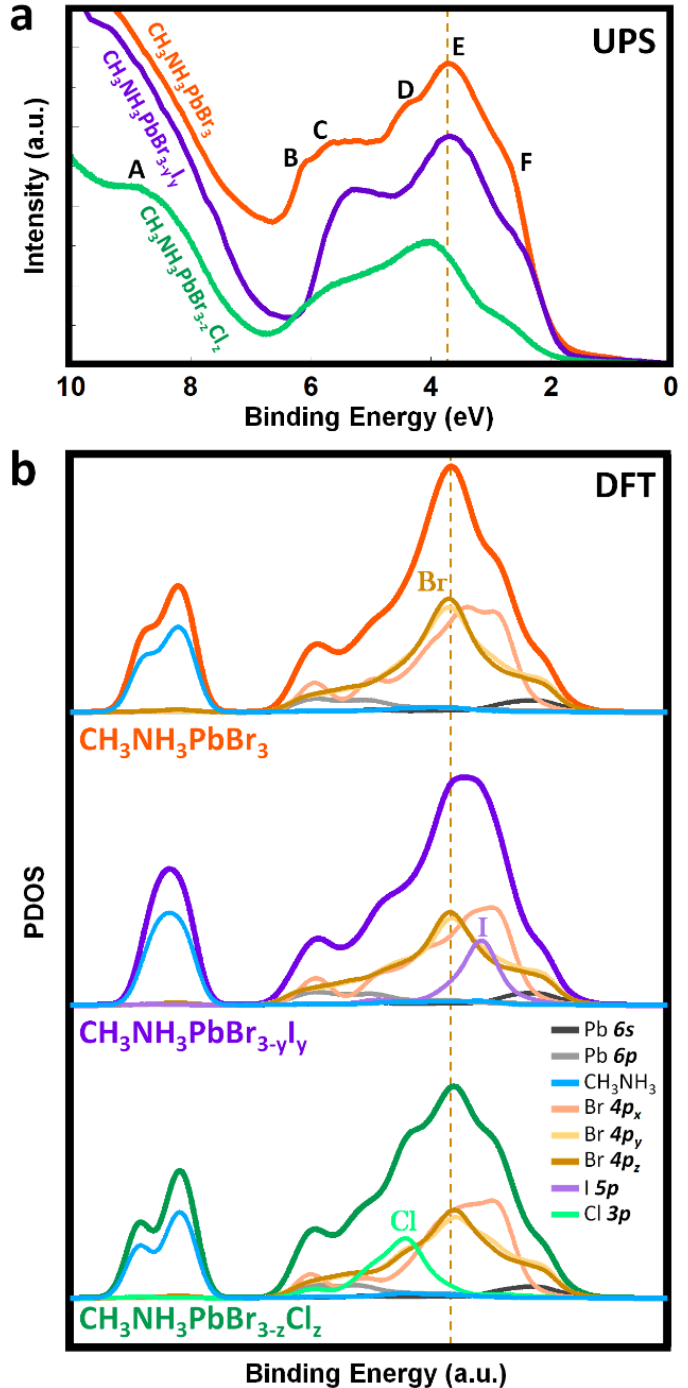

Figure 3. Valence band modification in mixed halide perovskite. a) Experimental ultra-violet photoelectron spectroscopy (UPS) spectra of pure $\mathrm{CH}_{3} \mathrm{NH}_{3} \mathrm{PbBr}_{3}$ (orange) and mixed $\mathrm{CH}_{3} \mathrm{NH}_{3} \mathrm{PbBr}_{3}$ $\mathrm{I}_{\mathrm{y}}$, (purple); $\mathrm{CH}_{3} \mathrm{NH}_{3} \mathrm{PbBr}_{3-\mathrm{z}} \mathrm{Cl}_{\mathrm{z}}$, (green) perovskites. b) Calculated PDOS of the pristine and mixed-halide perovskites. The Thick curves represents the summation of all contributions of each orbital indicated by differently colored lines. The PDOS were obtained for the full halide substitution of the perovskite surface.

To further understand the impact of halide substitution on the electronic properties of perovskite materials and its correlation with the stability, we evaluated the changes in the decomposition energy (see Methods) and bandgap of the $\mathrm{CH}_{3} \mathrm{NH}_{3} \mathrm{PbBr}_{3-}$ ${ }_{\mathrm{y}} \mathrm{I}_{\mathrm{y}}$ and $\mathrm{CH}_{3} \mathrm{NH}_{3} \mathrm{PbBr}_{3-\mathrm{z}} \mathrm{Cl}_{\mathrm{z}}$ films for different iodine and chlorine ratios. As depicted in Figure 4a, the substitution of bromine ions by iodine at the surface of the perovskite induces a decrease of the decomposition energy (purple curve) and a small but detectable reduction of the band gap (orange curve). In contrast, Figure $4 \mathrm{~b}$ shows that the incorporation of a small amount of chlorine (below $25 \%$, green curve) leads to an increase of the decomposition energy, with no substantial bandgap changes. 
a
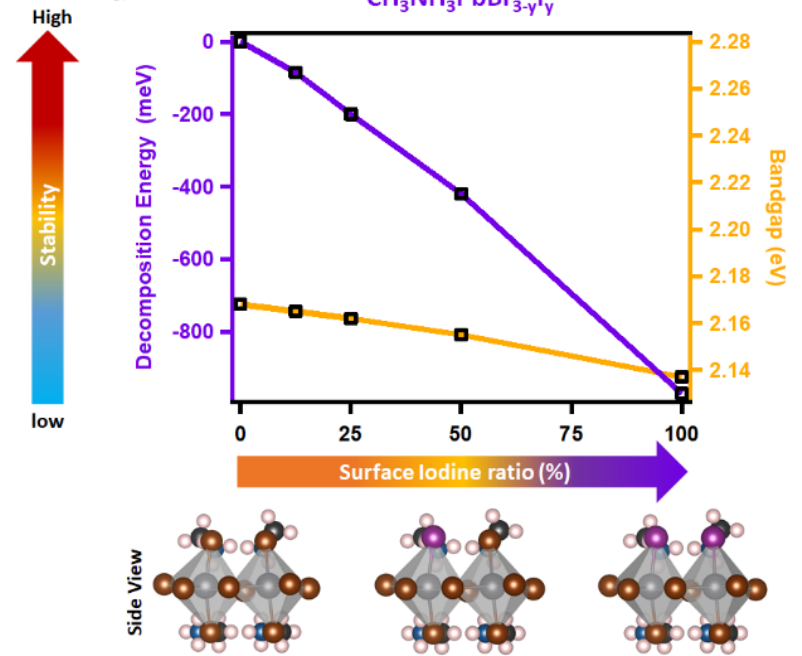

b

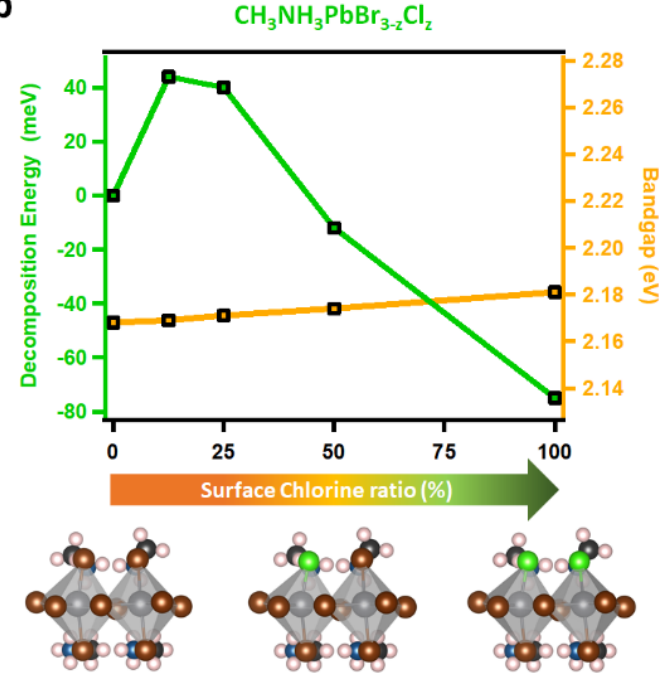

Figure 4. Stability versus bandgap change in mixed perovskite. (a-b) Decomposition energy difference between mixed-halide and pristine perovskite determined by DFT calculations (see methods). a) $\mathrm{CH}_{3} \mathrm{NH}_{3} \mathrm{PbBr}_{3-\mathrm{y}} \mathrm{I}_{\mathrm{y}}$ with increasing iodine content (y) at the surface. b) $\mathrm{CH}_{3} \mathrm{NH}_{3} \mathrm{PbBr}_{3-\mathrm{z}} \mathrm{Cl}_{\mathrm{z}}$ with increasing $\mathrm{Cl}$ content $(\mathrm{z})$ at the surface. The calculations were performed on a 6 layers slab with only the top layer being substituted. Bottom panels show the atomic structure of the pristine, half mixed, and completely substituted top surface of the perovskite. Color code: $\mathrm{Br}$ (brown), I(purple), $\mathrm{Cl}$ (green), C(black), $\mathrm{N}$ (light blue), $\mathrm{H}($ white).

An increase of the decomposition energy after chlorine substitution suggests higher stability of the perovskite film with respect to external stimuli such as temperature. This stability increase is related to the higher bond strength of $\mathrm{Cl}-\mathrm{Pb}$ compared to $\mathrm{Br}-\mathrm{Pb}$ and $\mathrm{I}-\mathrm{Pb}{ }^{29,30}$. Beyond the substitution ratio of $25 \%$, the strain induced by the incorporation of the smaller $\mathrm{Cl}$ ions with respect to $\mathrm{Br}$ counterbalances the benefit of the stronger $\mathrm{Cl}-\mathrm{Pb}$ bond strength and results in a lowering of the material stability (decomposition energy). Thus, the stability in mixed-halide perovskite results from the interplay between the $\mathrm{Pb}$-halide bond strength that stabilizes the material and the strain induced by the halide substitution that lowers decomposition energy. Based on our results, we suggest that as a general trend, substitution of the original surface halide atoms by a different halide with a smaller ions size and a higher $\mathrm{Pb}$-halide bond strength leads to an increase of the decomposition energy of the system, which in turn increases the material stability. Our DFT finding shows a stability increase without a strong bandgap modification. Although here only the substitution at the surface is considered, these results indicate that there may exist an optimal bulk $\mathrm{Cl}$ substitution ratio that would provide higher stability without substantially changing the bandgap of the perovskite material.

To further confirm these findings experimentally, we have studied the stabilization effect of chlorine on an actual solar cell

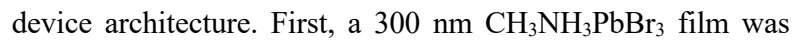
spun on a $\mathrm{TiO}_{2} / \mathrm{FTO} /$ Glass substrate (see Methods), which resembles the half (up to the perovskite layer) of a standard perovskite solar cell structure. Thereafter, the half-cell architecture was transferred into the UHV system, where chlorine was incorporated into the perovskite film by further $\mathrm{PbCl}_{2}$ vacuum evaporation. The degradation was then investigated by $\mathrm{x}$-ray photoelectron spectroscopy (XPS) for the half-cell samples with different $\mathrm{Cl}$ substitution ratios at the surface (Figure 5).
First, the evolution of the $\mathrm{Pb} 4 f$ peak was monitored for the pure $\mathrm{CH}_{3} \mathrm{NH}_{3} \mathrm{PbBr}_{3}$ film without the incorporation of $\mathrm{Cl}$. Figure 5a shows that initially (at $\mathrm{T}=0 \mathrm{~h}$ ), the spectrum is composed of only two peaks at 137.9 and $142.8 \mathrm{eV}$, attributed to the spinorbit split $\mathrm{Pb} 4 f_{7 / 2}$ and $\mathrm{Pb} 4 f_{5 / 2}$ peaks, later referred to as $\mathrm{Pb}(2+)$. After $4 \mathrm{~h}$, additional peaks appear at low binding energies associated with the lower oxidation $\mathrm{Pb}(0)$ state. Such a state is associated with deterioration of the perovskite film ${ }^{31}$. Therefore, in the present study we use the $\mathrm{Pb}(0)$ peak evolution as an indicator of the perovskite degradation. A progressive and strong increase of the $\mathrm{Pb}(0)$ peak intensity is observed as a function of time, indicating that the pure $\mathrm{CH}_{3} \mathrm{NH}_{3} \mathrm{PbBr}_{3}$ film undergoes a fast degradation. In contrast, much slower degradation (i.e., a significantly reduced $\mathrm{Pb}(0)$ peak intensity after a given time) was observed for the samples with the additional $\mathrm{PbCl}_{2}$ evaporation (Figures $5 \mathrm{~b}, 5 \mathrm{c}$ ). The degradation process is further slowed down as the amount of chlorine substitution increases. When $12 \%$ of the $\mathrm{Br}$ ions are substituted by $\mathrm{Cl}$ at the perovskite surface, the $\mathrm{Pb}(0)$ peak emerged after $28 \mathrm{~h}$, while it only appears after $116 \mathrm{~h}$ for a $18 \%$ substitution ratio (Figure $5 \mathrm{~d}$ ). For comparison, the substitution at the perovskite surface in the STM image of Figure $2 \mathrm{c}$ is about $26 \%$. Substitution ratios were determine by measuring the $\mathrm{Cl}: \mathrm{Br}$ chemical ratio in XPS. A quantitative analysis of the remaining $\mathrm{Pb}(2+)$ species (i.e., undegraded $\mathrm{Pb}$ ions on the surface) after a given time is presented in Figure 5e. The results demonstrate experimentally that the incorporation of $\mathrm{Cl}$ improves stability of perovskite films. It has been reported that $\mathrm{CH}_{3} \mathrm{NH}_{3} \mathrm{PbBr}_{3}$ shows significantly better stability than $\mathrm{CH}_{3} \mathrm{NH}_{3} \mathrm{PbI}_{3}{ }^{32}$. Here in this study, we have shown that with the surface $\mathrm{Br}$ ions of $\mathrm{CH}_{3} \mathrm{NH}_{3} \mathrm{PbBr}_{3}$ partially substituted by $\mathrm{Cl}$ ions, the half-cell sample stability gets further enhancement. Such a result is expected to have strong implications for device applications. 

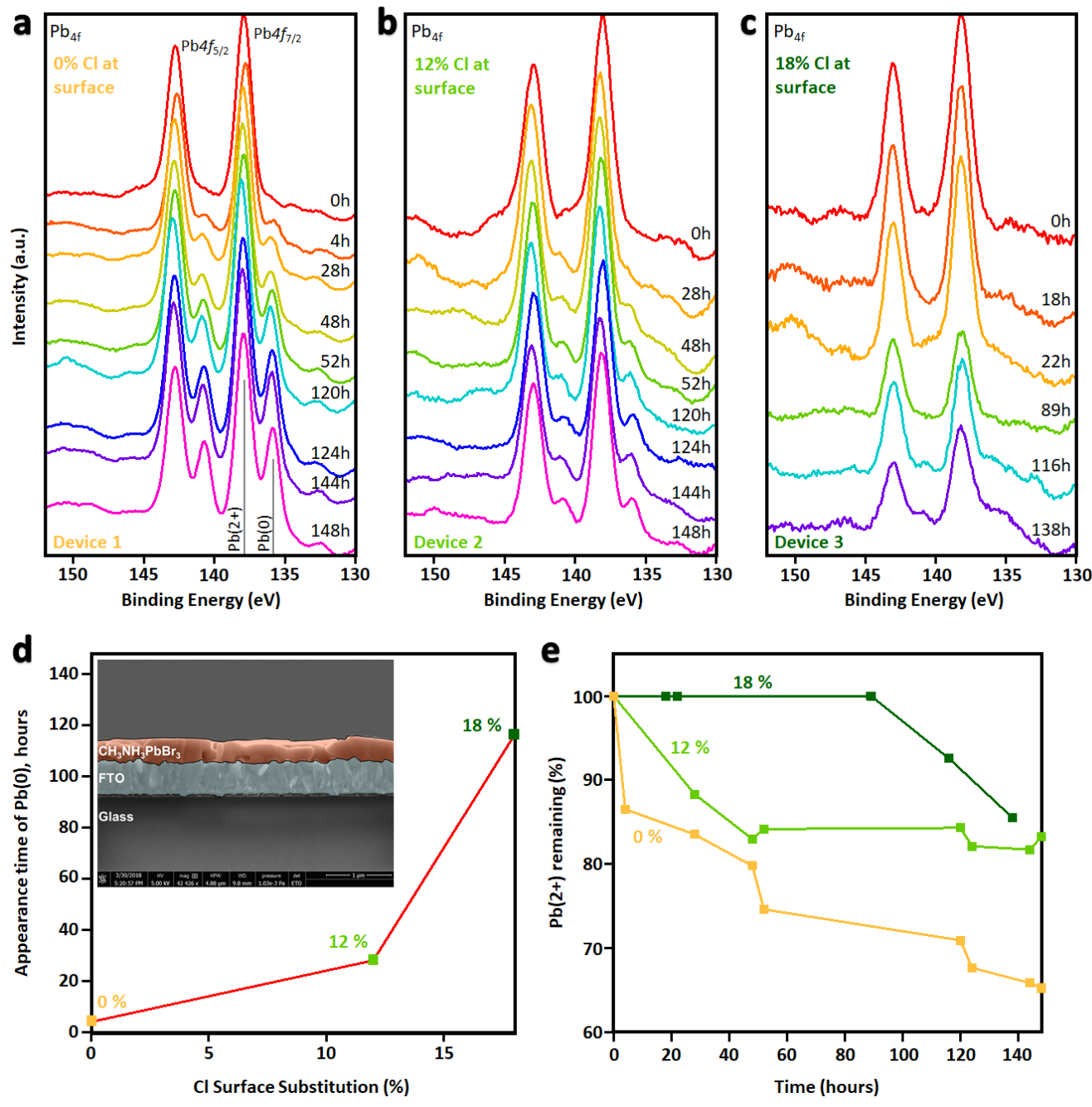

Figure 5. Beneficial aspects of halide mixing on perovskite stability. Time evolution of the $\mathrm{Pb} 4 \mathrm{f}$ peak obtained by $\mathrm{x}$-ray photoelectron spectroscopy (XPS) on a device architecture (a) without addition of chlorine, (b) with $12 \%$ of $\mathrm{Cl}$ at the surface, and (c) with $18 \% \mathrm{Cl}$ at the surface. d) Appearance time of $\mathrm{Pb}(0)$ feature with respect to the $\mathrm{Cl}$ substitution ratio at the surface. e) Time evolution of the percentage of $\mathrm{Pb}(2+)$ remaining for the different $\mathrm{Cl}$ substitution ratio at the surface.

\section{CONCLUSION}

We have determined for the first time the surface atomic structure of $\mathrm{CH}_{3} \mathrm{NH}_{3} \mathrm{PbBr}_{3-y} \mathrm{I}_{y}$ and $\mathrm{CH}_{3} \mathrm{NH}_{3} \mathrm{PbBr}_{3-\mathrm{z}} \mathrm{Cl}_{z}$ mixedhalide perovskite in real space, and correlate it to a corresponding enhancement or degradation of the stability of the compound. Using scanning tunneling microscopy combined with density functional theory we find that $\mathrm{Br}$ ions are replaced by the halide ions. The substituted halides are randomly distributed at the surface, showing a disordered atomic structure with no phase segregation. For the low substitution ratio (below 25\%), $\mathrm{Cl}$ and I affect in opposing ways to the work function and stability of the mixed perovskite. Our studies on device architectures demonstrate that the stability is increased after incorporating $12 \sim 18 \%$ of $\mathrm{Cl}$, which agrees with the calculated increase of the decomposition energy. Our results suggest that there is an optimal ratio of chlorine substitution which provides a maximum increase in stability without significant bandgap modification. This balance is an important direction for future device research, to address the perovskite stability issue, which remains one of the main challenge for industrial application.

\section{METHODS}

Surface characterization. $\mathrm{CH}_{3} \mathrm{NH}_{3} \mathrm{PbBr}_{3}$ perovskite films were grown on $\mathrm{Au}(111)$ single crystal using molecular beam epitaxy $^{22}$. First, the gold sample was cleaned in an ultrahigh vacuum environment $\left(\sim 1 \times 10^{-9}\right.$ torr) with several cycles of $\mathrm{Ne}^{+}$ sputtering followed by subsequent annealing at $773 \mathrm{~K}$ for $5 \mathrm{~min}$. Thereafter, $\mathrm{CH}_{3} \mathrm{NH}_{3} \mathrm{PbBr}_{3}$ was obtained by the co-deposition of $\mathrm{CH}_{3} \mathrm{NH}_{3} \mathrm{Br}$ and $\mathrm{PbBr}_{2}$ molecules at $361 \mathrm{~K}$ and $498 \mathrm{~K}$ respectively for $10 \mathrm{~min}$. During deposition, the gold surface was kept at $130 \mathrm{~K}$ to ensure the adhesion of the methyl-ammonium compound (MA). Mixed perovskites were obtained by sublimating $\mathrm{PbI}_{2}$ and $\mathrm{PbCl}_{2}$ on the $\mathrm{CH}_{3} \mathrm{NH}_{3} \mathrm{PbBr}_{3}$ film from Knudsen cells held at $525 \mathrm{~K}$ and $560 \mathrm{~K}$ respectively. During sublimation, the sample was kept at room temperature. Low-temperature scanning tunneling microscopy (LT-STM) was used to characterize the atomic-scale structures of the different perovskite ultra-thin films. The STM measurements were performed at $5 \mathrm{~K}$. A cut 
$\mathrm{Pt} / \mathrm{Ir}$ tip was used to acquire the STM images. The bias voltage was applied to the sample. X-ray photoelectron spectroscopy (XPS) and ultraviolet photoelectron spectroscopy (UPS) were performed in the same ultra-high vacuum (UHV) setup as the STM measurements, preventing any contamination from air.

Density functional theory. The calculations were performed using the VASP code ${ }^{33-35}$ with the projector augmented wave $(\mathrm{PAW})^{36}$ potential and Perdew-Burke-Ernzerhof $(\mathrm{PBE})^{37}$ exchange-correlation functional. For the unit cell, Brillouin zone (BZ) sampling was done using a $4 \times 4 \times 4$ Monkhorst-Pack grid. The $\mathrm{CH}_{3} \mathrm{NH}_{3} \mathrm{PbBr}_{3}(010)$ surfaces were modeled using $(2 \times 2)$ slabs containing six atomic layers. The size of the supercell was $(16.24 \times 16.54 \times 35.52) \AA$. A large vacuum thickness of $20 \AA$ along the direction normal to the surface was employed to separate surfaces from their periodic images. The bottom four layers of atoms were kept fixed at their optimized bulk positions. All other atoms were fully relaxed until the forces on each atom were smaller than $0.01 \mathrm{eV} / \AA$. The nonlocal van der Waals interactions were evaluated with the optB86-vdW functional ${ }^{38}$. The Gamma-centered Monkhorst-Pack sampling of $3 \times 3 \times 1$ was adopted to study the electronic properties of the surfaces of $\mathrm{CH}_{3} \mathrm{NH}_{3} \mathrm{PbBr}_{3}\left(\mathrm{MAPbBr}_{3}\right)$. From the electronic ground-state structure, STM images were calculated with the p4vasp code.

To evaluate the stability of the mixed perovskite, we consider the following reaction:

$$
2 \mathrm{MAPbBr}_{3}+y \mathrm{PbX}_{2} \rightarrow 2 \mathrm{MAPbBr}_{3-y} \mathrm{X}_{y}+y \mathrm{PbBr}_{2}
$$

Where $\mathrm{X}$ is $\mathrm{Cl}$ or $\mathrm{I}$, and $\mathrm{y} / 3$ is its ratio. The decomposition energy of the mixed perovskite $2 \mathrm{MAPbBr}_{3-y} \mathrm{X}_{y}$ is calculated as:

$$
E_{d e c}=E\left(\mathrm{MAPbBr}_{3-y} \mathrm{X}_{y}\right)-E\left(\mathrm{MAPbBr}_{3}\right)+\frac{y}{2}\left[E\left(\mathrm{PbBr}_{2}\right)-E\left(\mathrm{PbX}_{2}\right)\right]
$$

The stability of the perovskite is characterized by the decomposition energy $\left(E_{\mathrm{dec}}\right)$. The larger the decomposition energy, the more stable the material is.

Device fabrication. The patterned FTO glass (Pilkington, TEC- $8,8 \Omega / \mathrm{sq}$ ) was cleaned with detergent and DI water and sonicated with ethanol in an ultrasonic bath for $20 \mathrm{~min}$. UVOzone was treated for $15 \mathrm{~min}$ prior to use. The mesoporous $\mathrm{TiO}_{2}$ (ca. $50 \mathrm{~nm}$ ) layer was deposited by spin coating at 2000 $\mathrm{rpm}$ for $20 \mathrm{~s}$ (acceleration was $500 \mathrm{rpm} / \mathrm{s}$ ) using the diluted $\mathrm{TiO}_{2}$ solution in 1-butanol ${ }^{39}$. The deposited $\mathrm{TiO}_{2}$ film was annealed at $550{ }^{\circ} \mathrm{C}$ for $30 \mathrm{~min}$. The $\mathrm{CH}_{3} \mathrm{NH}_{3} \mathrm{PbBr}_{3}$ film was prepared via adduct method ${ }^{40}$. $0.367 \mathrm{~g}$ of $\mathrm{PbBr}_{2}$ (TCI) and $0.112 \mathrm{CH}_{3} \mathrm{NH}_{3} \mathrm{Br}$ (Dyesol) were dissolved in $0.6 \mathrm{~mL}$ of DMF with $75 \mu \mathrm{L}$ of DMSO at $60{ }^{\circ} \mathrm{C}$. The $\mathrm{CH}_{3} \mathrm{NH}_{3} \mathrm{Br}_{3}$ solution was spin-coated on the $\mathrm{mp}-\mathrm{TiO}_{2}$ substrate at $4000 \mathrm{rpm}$ for 20 and $0.3 \mathrm{~mL}$ of diethyl ether was poured when $10 \mathrm{~s}$ was remained. Then, it was dried on a hot plate at $100{ }^{\circ} \mathrm{C}$ for $20 \mathrm{~min}$.

\section{ASSOCIATED CONTENT}

\section{Supporting Information:}

1. Adsorption vs substitution in mixed-halide perovskite

2. Halide pairs and clusters at the surface of mixed perovskites

3. Determination of the valence band maximum (VBM)

4. Electrostatic potential and work-function changes

5. Device architecture
This material is available free of charge via the Internet at http://pubs.acs.org.

\section{AUTHOR INFORMATION}

\section{Corresponding Author}

* Yabing.Qi@OIST.jp,

*Yanfa.Yan@utoledo.edu

\section{Present Addresses}

$\dagger$ Department Physik, Universität Siegen, 57068 Siegen, Germany.

\section{ORCID IDs}

Jeremy Hieulle: 0000-0003-4891-4007

Xiaoming Wang: N/A

Collin Stecker: 0000-0003-4247-5699

Dae-Yong Son: 0000-0001-6898-5326

Longbin Qiu: 0000-0002-7696-4901

Robin Ohmann: 0000-0003-2483-1282

Luis K. Ono: 0000-0003-3176-1876

Aitor Mugarza: 0000-0002-2698-885X

Yanfa Yan: 0000-0003-3977-5789

Yabing Qi: 0000-0002-4876-8049

\section{Author Contributions}

The manuscript was written through contributions of all authors. All authors have given approval to the final version of the manuscript. $\$$ These authors contributed equally.

\section{Notes}

The authors declare no competing financial interest.

\section{ACKNOWLEDGMENT}

This work was supported by funding from the Energy Materials and Surface Sciences Unit of the Okinawa Institute of Science and Technology Graduate University, the OIST R\&D Cluster Research Program, the OIST Proof of Concept (POC) Program, and JSPS KAKENHI Grant Number JP18K05266. The work at The University of Toledo was supported by the Center for Hybrid Organic Inorganic Semiconductors for Energy (CHOISE), an Energy Frontier Research Center funded by the Office of Basic Energy Sciences, Office of Science within the US Department of Energy. The theoretical calculation part used the resources of the National Energy Research Scientific Computing Center, which is supported by the Office of Science of the U.S. Department of Energy under Contract No. DE-AC02-05CH11231.

\section{ABBREVIATIONS}

STM, scanning tunneling microscope; DFT, density functional theory; XPS, x-ray photoelectron spectroscopy; UPS, ultraviolet photoemission spectroscopy; FFT, fast Fourier transform; MA, methylammonium $\mathrm{CH}_{3} \mathrm{NH}_{3}$.

\section{REFERENCES}

(1) National Renewable Energy Laboratory (NREL). https://www.nrel.gov/pv/national-center-for-photovoltaics.html (2018).

(2) Noh, J.H.; Im, S.H.; Heo, J.H.; Mandal, T.N.; Seok, S.I. Chemical management for colorful, efficient, and stable inorganic-organic hybrid nanostructured solar cells. Nano Letters 2013, 13, 1764.

(3) Bush, K. A.; Palmstrom, A.F.; Yu, Z.J.; Boccard, M.; Cheacharoen, R.; Mailoa, J.P.; McMeekin, D.P.; Hoye, R.L.Z.; Bailie, C.D.; Leijtens, T.; Peters, I.M.; Minichetti, M.C.; Rolston, N.; Prasanna, R.; Sofia, S.; Harwood, D.; Ma, W.; Moghadam, F.; Snaith, H.J.; Buonassisi, T.; Holman, Z.C.; Bent, S.F.; McGehee, M.D. 23.6\%-efficient monolithic 
perovskite/silicon tandem solar cells with improved stability. Nat. Energy. 2017, 2, 17009.

(4) Jiang, F.; Rong, Y.; Liu, H; Liu, T.; Mao, L.; Meng, W.; Qin, F.; Jiang, Y.; Luo, B.; Xiong, S.; Tong, J.; Liu, Y.; Li, Z.; Han, H.; Zhou, $\mathrm{Y}$. Synergistic effect of $\mathrm{PbI}_{2}$ passivation and chlorine inclusion yielding high open-circuit voltage exceeding $1.15 \mathrm{~V}$ in both mesoscopic and inverted planar $\mathrm{CH}_{3} \mathrm{NH}_{3} \mathrm{PbI}_{3}(\mathrm{Cl})$-based perovskite solar cells. Adv. Funct. Mater. 2016, 26, 8119.

(5) Liu, J.; Prezhdo, O.V. Chlorine doping reduces electron-hole recombination in lead iodide perovskites: time-domain ab initio analysis. J. Phys. Chem. Lett. 2015, 6, 22, 4463.

(6) Yu, H.; Wang, F.; Xie, F.; Li, W.; Chen, J.; Zhao, N. The role of chlorine in the formation process of " $\mathrm{CH}_{3} \mathrm{NH}_{3} \mathrm{PbI}_{3-\mathrm{x}} \mathrm{Cl}_{\mathrm{x}}$ " perovskite. Adv. Funct. Mater. 2014, 24, 7102.

(7) Chen, Q.; Zhou, H.; Fang, Y.; Stieg, A.Z.; Song, T.-B.; Wang, H.H.; Xu, X.; Liu, Y.; Lu, S.; You, J.; Sun, P.; McKay, J.; Goorsky, M.S.; Yang, Y. The optoelectronic role of chlorine in $\mathrm{CH}_{3} \mathrm{NH}_{3} \mathrm{PbI}_{3}(\mathrm{Cl})$-based perovskite solar cells. Nat. Commun. 2015, 6, 7269 .

(8) Quarti, C.; Mosconi, E.; Umari, P.; De Angelis, F. Chlorine incorporation in the $\mathrm{CH}_{3} \mathrm{NH}_{3} \mathrm{PbI}_{3}$ perovskite: small concentration, big effect. Inorg. Chem. 2017, 56, 74.

(9) Colella, S.; Mosconi, E.; Pellegrino, G.; Alberti, A.; Guerra, V.L.P.; Masi, S.; Listorti, A.; Rizzo, A.; Condorelli, G.G.; De Angelis, F.; Gigli, G. Elusive presence of chloride in mixed halide perovskite solar cells. J. Phys. Chem. Lett. 2014, 5, 20, 3532.

(10) Jeon, N.J.; Noh, J.H.; Kim, Y.C.; Yang, W.S.; Ryu, S.; Seok, S.I. Solvent engineering for high-performance inorganic-organic hybrid perovskite solar cells. Nat. Mater. 2014, 13, 897.

(11) Lee, M.M.; Teuscher, J.; Miyasaka, T.; Murakami, T.N.; Snaith, H.J. Efficient hybrid solar cells based on meso-superstructured organometal halide perovskites. Science 2012, 338, 643.

(12) Zhang, M.; Yu, H.; Lyu, M.; Wang, Q.; Yun, J.-H.; Wang, L. Composition-dependent photoluminescence intensity and prolonged recombination lifetime of perovskite $\mathrm{CH}_{3} \mathrm{NH}_{3} \mathrm{PbBr}_{3-\mathrm{x}} \mathrm{Cl}_{\mathrm{x}}$ films. Chem. Commun. 2014, 50, 11727.

(13) Edri, E.; Kirmayer, S.; Cahen, D.; Hodes, G. High open-circuit voltage solar cells based on organic-inorganic lead bromide perovskite. J. Phys. Chem. Lett. 2013, 4, 897.

(14) Edri, E.; Kirmayer, S.; Kulbak, M.; Hodes, G.; Cahen, D. Chloride inclusion and hole transport material doping to improve methyl ammonium lead bromide perovskite-based high open-circuit voltage solar cells. J. Phys. Chem. Lett. 2014, 5, 429.

(15) Ono, L.K.; Juarez-Perez, E.J.; Qi, Y.B. Progress on perovskite materials and solar cells with mixed cations and halide anions. ACS Appl. Mater. Interfaces 2017, 9, 30197.

(16) Zhou, Y.; Zhou, Z.; Chen, M.; Zong, Y.; Huang, J.; Pang, S.; Padture, N.P. Doping and alloying for improved perovskite solar cells. J. Mater. Chem. A 2016, 4, 17623.

(17) Yin, W.-J.; Yang, J.-H.; Kang, J.; Yan, Y.; Wei, S.-H. Halide perovskite materials for solar cells: a theoretical review. J. Mater. Chem. A 2015, 3, 8926.

(18) Ye, M.; Hong, X.; Zhang, F.; Liu, X. Recent advancements in perovskite solar cells: flexibility, stability and large scale. J. Mater. Chem. A 2016, 4, 6755.

(19) Pool, V.L.; Gold-Parker, A.; McGehee, M.D.; Toney, M.F. Chlorine in $\mathrm{PbCl}_{2}$-derived hybrid-perovskite solar absorbers. Chem. Mater. 2015, 27, 7240 .

(20) Luo, S.; Daoud, W.A. Crystal structure formation of $\mathrm{CH}_{3} \mathrm{NH}_{3} \mathrm{PbI}_{3}$ ${ }_{\mathrm{x}} \mathrm{Cl}_{\mathrm{x}}$ perovskite. Materials 2016, 9, 123.

(21) Zhang, T.; Yang, M.; Benson, E.E.; Li, Z.; Lagemaat, J.; Luther, J.M.; Yan, Y; Zhu, K; Zhao, Y. A facile solvothermal growth of single crystal mixed halide perovskite $\mathrm{CH}_{3} \mathrm{NH}_{3} \mathrm{~Pb}\left(\mathrm{Br}_{1-\mathrm{x}} \mathrm{Cl}_{\mathrm{x}}\right)_{3}$. Chem. Commun. 2015, 51, 7820.

(22) Ono, L.K.; Wang, S.; Kato, Y.; Raga, S.R.; Qi, Y.B. Fabrication of semi-transparent perovskite films with centimeter-scale superior uniformity by the hybrid deposition method. Energy Environ. Sci. 2014, 7, 3989.

(23) Ohmann, R.; Ono, L.K.; Kim, H.-S.; Lin, H.; Lee, M.V.; Li, Y.; Park, N.-G.; Qi, Y.B. Real-space imaging of the atomic structure of organic-inorganic perovskite. J. Am. Chem. Soc. 2015,137, 16049.

(24) Hieulle, J.; Stecker, C.; Ohmann, R.; Ono, L.K.; Qi, Y.B. Scanning probe microscopy applied to organic-inorganic halide perovskite materials and solar cells. Small Methods 2018, 2, 1700295.

(25) She, L.; Liu, M.; Zhong, D. Atomic structures of $\mathrm{CH}_{3} \mathrm{NH}_{3} \mathrm{PbI}_{3}(001)$ surfaces. ACS Nano 2016, 10, 1126.

(26) Kedem, N.; Kulbak, M.; Brenner, T.M.; Hodes, G.; Cahen, D. Type-inversion as a working mechanism of high voltage MAP$\mathrm{bBr}_{3}(\mathrm{Cl})$-based halide perovskite solar cells. Phys. Chem. Chem. Phys. 2017, 19, 5753.

(27) Olthof, S.; Meerholz, K. Substrate-dependent electronic structure and film formation of $\mathrm{MAPbI}_{3}$ perovskites. Sci. Rep. 2017, 7, 40267.

(28) Comin, R.; Walters, G.; Thibau, E.S.; Voznyy, O.; Lu, Z.-H.; Sargent, E.H. Structural, optical, and electronic studies of wide-bandgap lead halide perovskites. J. Mater. Chem. C 2015, 3, 8839.

(29) Darwent, B. deB. National Standard Reference Data Series. National Bureau of Standards, Washington, D.C. 1970, 31.

(30) Cottrell, T.L. The Strengths of Chemical Bonds, $2^{\text {nd }}$ Edition, Butterworth, London 1958.

(31) Juarez-Perez, E.J.; Ono, L.K.; Maeda, M.; Jiang, Y.; Hawash, Z.; Qi, Y.B. Photodecomposition and thermal decomposition in methylammonium halide lead perovskites and inferred design principles to increase photovoltaic device stability. J. Mater. Chem. A 2018, 6, 9604.

(32) Pont, S; Bryant, D.; Lin, C.-T.; Aristidou, N.; Wheeler, S.; Ma, X.; Godin, R.; Haque, S.A.; Durrant, J.R. Tuning $\mathrm{CH}_{3} \mathrm{NH}_{3} \mathrm{~Pb}\left(\mathrm{I}_{1-\mathrm{x}} \mathrm{Br}_{\mathrm{x}}\right)_{3}$ perovskite oxygen stability in thin films and solar cells. J. Mater. Chem. A 2017, 5, 9553 .

(33) Kresse, G.; Hafner, J. Ab initio. Phys. Rev. B 1993, 47, 558.

(34) Kresse, G.; Furthmüller, J. Efficiency of ab-initio total energy calculations for metals and semiconductors using a plane-wave basis set. Comput. Mater. Sci. 1996, 6, 15.

(35) Kresse, G.; Furthmüller, J. Efficient iterative schemes for ab initio total-energy calculations using a plane-wave basis set. Phys. Rev. B 1996, 54, 11169.

(36) Blöchl, P.E. Projector augmented-wave method. Phys. Rev. B 1994, 50, 17953.

(37) Perdew, J.P.; Burke, K.; Ernzerhof, M. Generalized gradient approximation made simple. Phys. Rev. Lett. 1996, 77, 3865.

(48) Klimeš, J.; Bowler, D.R.; Michaelides, A. Van der Waals density functionals applied to solids. Phys. Rev. B 2011, 83, 195131.

(39) Son, D.-Y.; Lee, J.W.; Choi, Y.J.; Jang, I.H.; Lee, S.; Yoo, P.J.; Shin, H.; Ahn, N.; Choi, M.; Kim, D.; Park, N.-G. Self-formed grain boundary healing layer for highly efficient $\mathrm{CH}_{3} \mathrm{NH}_{3} \mathrm{PbI}_{3}$ perovskite solar cells. Nat. Energy. 2016, 1, 16081.

(40) Ahn, N.; Son, D.-Y.; Jang, I.H.; Kang, S.M.; Choi, M.; Park, N.G. Highly reproducible perovskite solar cells with average efficiency of $18.3 \%$ and best efficiency of $19.7 \%$ fabricated via Lewis base adduct of lead(II) iodide. J. Am. Chem. Soc. 2015, 137, 8696. 